\title{
Tingkat Konsumsi Kalsium, Seng, Vitamin E dan Dismenorea Primer pada Siswi SMA
}

\section{Consumption Level of Calcium, Zinc, Vitamin $E$ and Primary Dysmenorrhea in the Students at Senior High School}

\author{
Putu Datisia Werdi Saraswati ${ }^{1}$, I Putu Suiraoka ${ }^{2}$, A.A Ngurah Kusumajaya ${ }^{3}$ \\ Jurusan Gizi, Politeknik Kesehatan Denpasar, Indonesia
}

\begin{tabular}{l} 
ARTICLE INFO \\
\hline Article history \\
Received date \\
01 Oct 2020 \\
Revised date \\
09 Oct 2020 \\
12 Oct 2020 \\
Accepted date \\
20 Oct 2020 \\
\hline
\end{tabular}

Keywords:

Consumption level of calcium;

Primary dysmenorea;

Vitamin E;

Zinc.

Kata kunci:

Tingkat konsumsi

kalsium;

Dismenorea primer;

Vitamin E;

Seng.

\begin{abstract}
ABSTRAK
Total of $54,89 \%$ of childbearing age women in Indonesia experience primary dysmenorrhea. The intake of micronutrients such as Calcium, Zinc, Vitamin E can help in relieving the pain. This study aimed to find out the relationship between the level of calcium, zinc, and vitamin $\mathrm{E}$ consumption with the primary dysmenorrhea in female students at SMA Negeri 8 Denpasar. This study used observational research with a crosssectional approach to support the research. 65 people were taken as samples using the simple random sampling technique. The chi-square was used as the statistical test in this study. The result of the study showed that most of the samples had low-level consumption of Calcium (87,7\%), Zinc (78,5\%), and vitamin E (95.4\%), and 70,8\% of the samples had primary dysmenorrhea. Based on the result, there was a relationship between the level of Calcium, Zinc, and Vitamin E consumption with primary dysmenorrhea. The better level of Calcium, Zinc, and Vitamin E consumption, the fewer women will experience dysmenorrhea. It is necessary to provide counseling that is related to alternative dysmenorrhea prevention, especially regarding the role of nutrients that can be used as dysmenorrhea therapy.
\end{abstract}

\begin{abstract}
Di Indonesia, sebanyak 54,89\% wanita usia subur mengalami dismenorea primer. Asupan zat gizi mikro dapat membantu dalam mengatasi keluhan ini, adapun diantaranya yaitu kalsium, seng dan vitamin E. Penelitian ini bertujuan untuk mengetahui hubungan tingkat konsumsi kalsium, seng dan vitamin E dengan dismenorea primer pada siswi di SMA Negeri 8 Denpasar. Jenis penelitian ini bersifat observasional dengan pendekatan cross-sectional. Jumlah sampel 65 orang diambil menggunakan teknik simple random sampling. Uji statistik menggunakan uji chi square. Hasil penelitian menunjukkan sebagian besar sampel memiliki tingkat konsumsi kalsium $(87,7 \%)$, seng $(78,5 \%)$ dan vitamin E $(95,4 \%)$ dengan kategori kurang dan sebanyak $70,8 \%$ sampel mengalami dismenorea primer. Hasil penelitian menunjukkan adanya hubungan tingkat konsumsi kalsium, seng dan vitamin E dengan kejadian dismenorea primer. Semakin baik tingkat konsumsi kalsium, seng dan vitamin E maka semakin rendah kejadian dismenorea. Perlu diberikannya penyuluhan terkait alternatif pencegahan atau penanggulangan dismenorea khususnya mengenai peran zat gizi yang dapat digunakan sebagai terapi dismenorea.
\end{abstract}

Corresponding Author:

Putu Datisia Werdi Saraswati

Jurusan Gizi, Politeknik Kesehatan Denpasar, Indonesia

Email: putudatisiawerdhi05@gmail.com

\section{PENDAHULUAN}

Seorang anak mengalami perubahan fisik dan psikis pada tubuhnya saat usia remaja sebagai tanda telah memasuki masa pubertas.
Salah satunya seperti remaja putri yang akan mengalami menstruasi. Pada saat terjadinya menstruasi beberapa remaja putri akan mengalami masalah tidak nyaman berupa nyeri. Nyeri yang dirasakan saat terjadinya menstruasi 
disebut dengan dismenorea. Dismenorea dapat dibagi menjadi 2 yaitu dismenorea primer dan dismenorea sekunder (Devi, 2012). Dismenorea primer adalah nyeri pada bagian bawah perut yang terjadi saat wanita mengalami siklus menstruasi yang dipengaruhi oleh gangguan keseimbangan hormon tanpa adanya kelainan organ reproduksi dan sering dirasakan saat usia remaja (Ratnawati, 2017). Hal ini disebabkan oleh hormon prostaglandin yang meningkat, yang disebabkan oleh menurunnya hormon-hormon estrogen dan progesteron menyebabkan endometrium yang membengkak dan mati karena tidak dibuahi (Nugroho \& Indra, 2014). Selain rasa nyeri pada bagian bawah perut yang dirasakan, dismenorea primer ini juga memiliki beberapa gejala penyerta seperti nyeri punggung, pegal-pegal, pusing, mual, lemas, muntah, diare dan penurunan nafsu makan. Sedangkan dismenorea sekunder gejalanya hampir sama dengan dismenorea primer tetapi dapat terjadinya pendarah hebat selama $>7$ hari selama menstruasi biasanya dirasakan pada usia 25-30 tahun (Nathan 2005 dalam Silviana, 2012). Di Indonesia sebanyak $54,89 \%$ wanita usia subur mengalami dismenorea primer (Proverawati dan Misaroh, 2009 dalam Karlina, 2014). Beberapa penelitian juga menunjukkan sebagian besar remaja putri mengalami dismenorea seperti pada SMA Siswi Kelas XI SMA Negeri 52 Jakarta, didapatkan hasil sebanyak $86 \%$ siswi mengalami dismenorea, dari hasil tersebut sebanyak $92 \%$ menyatakan bahwa aktivitas belajar menjadi terganggu (Putri, dkk., 2017). Penelitian pada remaja putri di SMA Negeri 1 Sukawati diperoleh hasil bahwa 75,9\% mengalami dismenorea (Casteli, 2018). Dismenorea primer ini dapat terjadi karena kurangnya pemahaman terkait gizi sehingga berdampak pada rendahnya konsumsi makanan yang mengandung zat gizi mikro khususnya kalsium, seng dan vitamin E. Zat gizi tersebut berperan dalam proses pertumbuhan dan perkembangan tubuh, selain itu juga dapat mencegah terjadinya gangguan saat menstruasi (Devi, 2012).

Berdasarkan hasil studi pendahuluan yang dilakukan pada siswi SMA Negeri 8 Denpasar pada bulan Juli 2019, dari 20 siswi yang diwawancarai sebanyak 14 orang (70\%) mengalami dismenorea primer dan sebanyak 6 orang siswi (30\%) tidak mengalami dismenorea. Sebagian besar siswi yang diwawancarai rata-rata mengalami kenaikan nafsu makan dan ada juga yang mengalami penurunan nafsu makan menjelang menstruasi. Hal tersebut akan merubah pola makan siswi yang akan berdampak pada kesehatan tubuh, khususnya saat menstruasi dengan kejadian dismenorea. Berdasarkan latar belakang tersebut, maka peneliti tertarik meneliti tentang hubungan tingkat konsumsi kalsium, seng dan vitamin $\mathrm{E}$ dengan kejadian dismenorea primer pada siswi di SMA Negeri 8 Denpasar.

Tujuan penelitian ini adalah untuk mengetahui hubungan yang signifikan antara tingkat konsumsi kalsium, seng dan vitamin E dengan kejadian dismenorea primer pada siswi di SMA Negeri 8 Denpasar.

\section{METODE}

Penelitian dilakukan di SMA Negeri 8 Denpasar pada bulan Maret 2020. Jenis penelitian ini adalah observasional dengan rancangan cross sectional. Populasi pada penelitian ini adalah seluruh siswi kelas X, XI dan XII SMA Negeri 8 Denpasar, sedangkan populasi target yaitu siswi kelas XI berjumlah 201 orang siswi. Besar sampel pada penelitian ini berjumlah 65 orang siswi dengan menggunakan teknik simple random sampling dan pengambilan sampel per-kelas menggunakan cara proporsional. Data yang dikumpulkan adalah data tingkat konsumsi kalsium, seng dan vitamin E dikumpulkan dengan cara wawancara menggunakan form recall 24 jam. Kemudian dikonversikan ke dalam zat gizi kalsium, seng dan vitamin $\mathrm{E}$ dengan bantuan komputer. Hasilnya dibandingkan dengan kebutuhan per individu. Kemudian dikategorikan berdasarkan tingkat konsumsinya yaitu kurang $(<80 \%)$, baik (80-100\%) dan lebih (>100\%). Data dismenorea primer didapatkan dengan cara wawancara langsung kepada sampel menggunakan kuesioner. Data dismenorea akan dikelompokkan berdasarkan 2 kategori yaitu dismenorea primer jika mengalami rasa nyeri pada perut bagian bawah saat siklus menstruasi disertai beberapa gejala penyerta seperti nyeri punggung, pegalpegal, pusing, mual, lemas, muntah, diare dan penurunan nafsu makan dan tidak dismenorea primer jika tidak mengalami gejala nyeri perut bagian bawah dan gejala penyerta saat siklus menstruasi atau mengalami dismenorea sekunder yaitu mengalami nyeri perut bagian bawah dengan kelainan organ reproduksi disertai pendarahan hebat selama 7 hari saat siklus menstruasi. Data yang diperoleh selanjutnya dianalisis menggunakan tabel distribusi frekuensi dan keterkaitan antar variabel yang dianalisis menggunakan uji chi square.

Penelitian ini telah mendapatkan Persetujuan Etik (Ethical Approval) dengan Nomor: LB.02.03/EA/KEPK/0427/2019 oleh 
Ketua Komisi Etik Penelitian Kesehatan Poltekkes Denpasar.

\section{HASIL}

Tabel 1. Karakteristik sampel

\begin{tabular}{lll}
\hline \multicolumn{1}{c}{ Variabel } & f & \% \\
\hline Umur & & \\
16 tahun & 31 & 47,7 \\
17 tahun & 34 & 52,3 \\
Keteraturan menstruasi & & \\
Teratur & 55 & 84,6 \\
Tidak teratur & 10 & 15,4 \\
\hline
\end{tabular}

Berdasarkan tabel 1 sebaran umur sampel didapatkan sebagian besar sampel berumur 17 tahun yaitu sebanyak 34 orang $(52,3 \%)$. Jika dilihat dari keteraturan siklus menstruasi dalam satu periode dapat diketahui bahwa sebagian besar memiliki menstruasi yang teratur yaitu 55 sampel $(84,6 \%)$.

\section{Tabel 2. Tingkat Konsumsi Zat Gizi}

\begin{tabular}{lrr}
\hline \multicolumn{1}{c}{ Tingkat konsumsi } & f & \% \\
\hline Kalsium & & \\
Kurang & 57 & 87,7 \\
Baik & 8 & 12,3 \\
Seng & & \\
$\quad$ Kurang & 51 & 78,5 \\
$\quad$ Baik & 14 & 21,5 \\
Vitamin E & & \\
$\quad$ Kurang & 62 & 95,4 \\
Baik & 3 & 4,6 \\
\hline
\end{tabular}

Berdasarkan hasil yang diperoleh pada tabel 2 bahwa tingkat konsumsi kalsium sebanyak 57 sampel $(87,7 \%)$, tingkat konsumsi seng sebanyak 51 sampel $(78,5 \%)$, dan tingkat konsumsi vitamin E sebanyak 62 sampel $(95,4 \%)$ yang telah dibandingkan dengan kebutuhan perindividu maka dikategorikan kurang.

\section{Tabel 3. Dismenorea primer}

\begin{tabular}{lrr}
\hline \multicolumn{1}{c}{ Variabel } & f & \multicolumn{1}{c}{$\%$} \\
\hline Dismenorea & & \\
Dismenorea primer & 46 & 70,8 \\
Tidak dismenorea primer & 19 & 29,2 \\
Total & 65 & 100,0 \\
Ketergangguan & & \\
Tidak terganggu & 21 & 45,7 \\
Terganggu & 25 & 54,3 \\
Total & 46 & 100,0 \\
\hline
\end{tabular}

Dalam mengategorikan dismenorea primer dengan syarat sampel mengalami rasa nyeri pada perut bagian bawah saat siklus menstruasi, dan tidak ada kelainan dalam organ reproduksi, sehingga sesuai pada tabel 3 didapatkan hasil sebanyak 46 sampel $(70,8 \%)$ mengalami dismenorea primer, dan dari 46 sampel yang mengalami dismenorea primer sebanyak 25 sampel $(54,3 \%)$ merasakan aktivitas sekolah menjadi terganggu.

Tabel 4. Tingkat Konsumsi Kalsium menurut Status Dismenorea

\begin{tabular}{lrrrrrr}
\hline $\begin{array}{c}\text { Tingkat } \\
\text { Konsumsi } \\
\text { Kalsium }\end{array}$ & \multicolumn{2}{c}{$\begin{array}{c}\text { Status Dismenorea } \\
\text { Dismenorea } \\
\text { Primer }\end{array}$} & $\begin{array}{c}\text { Tidak } \\
\text { Dismenorea }\end{array}$ & \multicolumn{2}{c}{ Total } \\
& \multicolumn{1}{c}{ f } & \multicolumn{1}{c}{$\%$} & \multicolumn{1}{c}{ f } & \multicolumn{1}{c}{$\%$} & \multicolumn{1}{c}{ f } & \multicolumn{1}{c}{$\%$} \\
\hline Kurang & 46 & 100,0 & 11 & 57,8 & 57 & 87,6 \\
Baik & 0 & 0,0 & 8 & 42,2 & 8 & 12,4 \\
Total & 46 & 100,0 & 19 & 100,0 & 65 & 100,0 \\
\hline
\end{tabular}

Berdasarkan tabel 4 dari 46 sampel yang mengalami dismenorea primer seluruhnya (100\%) memiliki tingkat konsumsi kalsium kurang. Sedangkan dari 19 sampel yang tidak mengalami dismenorea primer, sebanyak 8 sampel $(42,2 \%)$ memiliki tingkat konsumsi baik.

Setelah dilakukan analisis statistik dengan menggunakan uji Chi-Square diperoleh hasil $p$ value $=0,000 \quad(\alpha<0,005)$ yang berarti secara statistik ada hubungan antara tingkat konsumsi kalsium dengan dismenorea primer.

Tabel 5. Tingkat Konsumsi Seng menurut Status Dismenorea

\begin{tabular}{|c|c|c|c|c|c|c|}
\hline \multirow{3}{*}{$\begin{array}{l}\text { Tingkat } \\
\text { Konsumsi } \\
\text { Seng }\end{array}$} & \multicolumn{4}{|c|}{ Status Dismenorea } & \multirow{2}{*}{\multicolumn{2}{|c|}{ Total }} \\
\hline & \multicolumn{2}{|c|}{$\begin{array}{c}\text { Dismenorea } \\
\text { Primer }\end{array}$} & \multicolumn{2}{|c|}{$\begin{array}{c}\text { Tidak } \\
\text { Dismenorea } \\
\text { Primer }\end{array}$} & & \\
\hline & f & $\%$ & $\mathbf{f}$ & $\%$ & f & $\%$ \\
\hline Kura & 44 & 95,6 & 7 & 36,8 & 51 & 78,4 \\
\hline $\mathrm{Ba}$ & 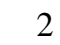 & 44 & 12 & 63,2 & 14 & \\
\hline Total & 46 & 100,0 & 19 & 100,0 & 65 & 100,0 \\
\hline
\end{tabular}

Pada tabel 5 dilihat dari 46 sampel yang mengalami dismenorea primer sebanyak 44 sampel $(96 \%)$ yang memiliki tingkat konsumsi seng kurang. Sedangkan sebanyak 12 sampel (63\%) dari 19 sampel yang tidak mengalami dismenorea primer memiliki tingkat konsumsi baik.

Setelah dilakukan analisis statistik dengan menggunakan uji Chi-Square diperoleh hasil $p$ value $=0,000 \quad(\alpha<0,005)$ yang berarti secara statistik ada hubungan antara tingkat konsumsi seng dengan dismenorea primer. 
Tabel 6. Tingkat Konsumsi Vitamin E menurut Status Dismenorea

\begin{tabular}{lrrrrrr}
\hline \multicolumn{1}{c}{$\begin{array}{c}\text { Tingkat } \\
\text { konsumsi }\end{array}$} & \multicolumn{2}{c}{$\begin{array}{c}\text { Status Dismenorea } \\
\text { Dismenorea } \\
\text { vitamin E }\end{array}$} & \multicolumn{2}{c}{$\begin{array}{c}\text { Tidak } \\
\text { Primer }\end{array}$} & $\begin{array}{c}\text { Dismenorea } \\
\text { Primer }\end{array}$ & \multicolumn{2}{c}{ Total } \\
& f & \% & \multicolumn{1}{c}{ f } & \% & \multicolumn{1}{c}{ f } & \multicolumn{1}{c}{$\%$} \\
\hline Kurang & 45 & 97,8 & 17 & 89,4 & 62 & 95,3 \\
Baik & 1 & 2,2 & 2 & 10,6 & 3 & 4,7 \\
Total & 46 & 100,0 & 19 & 100,0 & 65 & 100,0 \\
\hline
\end{tabular}

Pada tabel 6 sebanyak 45 sampel (98\%) yang mengalami dismenorea primer memiliki tingkat konsumsi vitamin E kurang. Dari 19 sampel yang tidak mengalami dismenorea primer, dan hanya 2 sampel (10\%) tingkat konsumsi vitamin E baik.

Setelah dilakukan analisis statistik dengan menggunakan uji Chi-Square diperoleh hasil $p$ value $=0,144 \quad(\alpha>0,005)$ yang berarti secara statistik tidak ada hubungan antara tingkat konsumsi vitamin E dengan dismenorea primer

\section{PEMBAHASAN}

Dalam satu periode siklus menstruasi diketahui bahwa sebagian besar sampel menyatakan bahwa siklus menstruasi teratur $(84,6 \%)$. Jika dilihat dari status dismenorea didapatkan hasil sebanyak 46 sampel $(70,8 \%)$ mengalami dismenorea primer. Sampel yang mengalami dismenorea primer mengalami beberapa gejala-gejala penyerta seperti nyeri pada punggung, pegal-pegal, pusing, lemas dan penurunan nafsu makan, gejala-gejala tersebut dialami sampel pada hari 1-2 saat menstruasi. Dismenorea primer ini adalah rasa sakit atau nyeri bagian bawah perut yang terjadi saat perempuan mengalami siklus menstruasi yang sering dirasakan saat usia remaja (Ratnawati, 2017). Dismenorea primer yang dirasakan oleh sebanyak 25 sampel $(54,3 \%)$ berakibat aktivitas sekolahnya menjadi terganggu, hal ini sejalan dengan hasil penelitian Setiawan \& Lestari, (2018) yang menyatakan bahwa terdapat hubungan nyeri haid (dismenorea) terhadap aktivitas belajar remaja putri di SMPN 3 Pulung hal ini terjadi karena rasa sakit yang timbul membuat remaja tersebut tidak konsentrasi dalam belajar sehingga timbul keinginan untuk tidak mengikuti mata pelajaran yang berlangsung dan menyebabkan siswa tersebut tertinggal mata pelajaran sekolahnya. Dismenorea ini dapat terjadi karena adanya peningkatan hormon prostaglandin yang disebabkan oleh menurunnya hormon-hormon estrogen dan progesteron menyebabkan endometrium yang membengkak dan mati karena tidak dibuahi. Peningkatan hormon prostaglandin ini menyebabkan otot-otot kandungan berkontraksi dan menghasilkan rasa nyeri (Sukarni \& Wahyu, 2013).

Sebaran sampel berdasarkan tingkat konsumsi kalsium yang telah dibandingkan dengan kebutuhan per individu, didapatkan hasil dari 65 sampel sebanyak 57 sampel $(87,7 \%)$ tergolong kategori kurang. Dilihat dari hasil recall kurangnya tingkat konsumsi kalsium dikarenakan sampel jarang mengonsumsi makanan yang mengandung sumber kalsium seperti produk susu atau olahannya, hati ayam, ikan laut, kacang-kacangan dan lainnya (Direktorat Jendral, 2018), walaupun ada jumlah dan frekuensinya sedikit. Selain itu kurangnya pengetahuan gizi akan berdampak pada perilaku makan seseorang yang berdampak pada asupan zat gizi seperti dalam penelitian Rahman, Dewi, \& Armawati (2016) bahwa kurangnya pengetahuan berdampak pada kurangnya mengonsumsi makanan yang mengandung zat gizi khususnya kalsium. Kebutuhan kalsium pada masa remaja ini menjadi hal yang penting dalam masa pertumbuhan dan perkembangan fisik, seperti kalsium berfungsi dalam kontraksi otot pada organ reproduksi (Almatsier, 2009).

Selain kebutuhan kalsium, zat gizi mikro lain seperti seng juga penting bagi remaja. Berdasarkan hasil yang didapatkan sebanyak 51 sampel (78,5\%) tergolong dalam tingkat konsumsi seng kurang. Kurangnya asupan seng pada sampel disebabkan oleh kebiasaan mengonsumsi sumber makanan yang kandungan sengnya sangat sedikit, selain itu pada usia ini remaja cenderung lebih memperhatikan keadaan fisik, sehingga tidak jarang mereka mulai melakukan diet yang berlebihan dengan mengurangi porsi makan tanpa memperhatikan kandungan gizi dalam makanan (Hendarini, 2018), jika dilihat dalam penelitian ini berdampak pada minimnya asupan seng. Kebutuhan akan seng pada masa remaja sangatlah perlu diperhatikan, karena seng bagian dari follicle stimulating hormone (FSH) dan luteinizing hormone $(\mathrm{LH})$ yang berfungsi penting dalam masa pertumbuhan dan kematangan seksual pada remaja (Mardalena, 2017).

Selain zat mineral seperti kalsium dan seng, vitamin juga dapat berperan penting dalam proses pertumbuhan dan perkembangan tubuh, salah satunya yaitu vitamin E. Vitamin E dikenal sebagai suatu antioksidan yang memegang peranan penting dalam melindungi asam lemak jenuh ganda dan komponen membran sel lain dari oksidasi radikal bebas (Almatsier, 2009). Pada tingkat konsumsi vitamin E sebanyak 62 
sampel $(95,4 \%)$ dikategorikan kurang, dan hanya 3 sampel $(4,6 \%)$ yang memiliki tingkat konsumsi baik. Hasil recall yang telah dilakukan masih banyak sampel kurang dalam mengonsumsi bahan makanan sumber vitamin $\mathrm{E}$, hal ini dilihat dari masih sedikitnya sampel mengonsumsi buah-buahan dan sayuran dengan alasan tidak suka. Sumber vitamin E tidak hanya ditemukan dalam sayuran dan buah-buahan saja, adapun bahan makanan yang mengandung vitamin $\mathrm{E}$ seperti minyak sayur, gandum, ikan laut, seafood, telur dan lainnya (Direktorat Jendral, 2018). Pada remaja putri yang berada pada masa pubertas vitamin $\mathrm{E}$ ini merupakan sumber antioksidan yang dapat mencegah terjadinya gangguan pada saat menstruasi (Mardalena, 2017).

Berdasarkan hasil analisis data statistik menunjukkan ada hubungan yang signifikan antara tingkat konsumsi kalsium dengan dismenorea primer dengan hasil $p$-value sebesar $0,000 \quad(\alpha<0,05)$. Hasil ini sejalan dengan penelitian yang dilakukan oleh Tih, dkk., (2017) pada perempuan usia 19-23 tahun yang mengalami dismenorea primer dan sindrom premenstruasi telah membuktikan bahwa pemberian suplemen kalsium $1.000 \mathrm{mg} / \mathrm{hari}$ dapat mengurangi skala nyeri saat siklus menstruasi. Penelitian lain juga dilakukan oleh Febriani, Ariani, dan Kusumastuty (2018) yang dilakukan di SMK 2 Malang yaitu memberikan susu sapi dengan kandungan kalsium 1000mg sebanyak 2 kali dalam rentang waktu 4 jam selama 8 jam penelitian ini terbukti efektif dalam meredakan intensitas nyeri dismenorea. Para peneliti meyakini bahwa kalsium memainkan peran dalam mengurangi rasa sakit saat dismenorea dengan mengontrol aktivitas neuromuscular pada rahim akibat hormon prostaglandin yang berlebihan.

Secara statistik didapatkan hasil bahwa ada hubungan yang signifikan antara tingkat konsumsi seng dengan dismenorea primer, diperoleh hasil $p$-value sebesar $0,000 \quad(\alpha<0,05)$. Penelitian ini sejalan dengan hasil penelitian Farrah, Halim, dan Kaban (2017) bahwa ada hubungan yang signifikan antara efektivitas suplemen zinc dalam mengobati dismenorea, penelitian ini dilakukan pada pasien dengan nyeri haid parah di Rumah Sakit H Adam Malik dan Rumah Sakit Satelit lainnya dengan memberikan suplemen zinc sebanyak $30 \mathrm{mg}$ per hari $(15 \mathrm{mg} 2$ kali sehari), dua hari sebelum tanggal perkiraan menstruasi sampai periode menstruasi berakhir terbukti dapat menurunkan intensitas nyeri dismenorea. Penelitian lain yang dilakukan oleh Damayanti, Sunarsih, dan Utami (2020) juga menyatakan bahwa ada hubungan pengaruh pemberian zinc terhadap penurunan rasa nyeri saat menstruasi (dismenorea). Selain dari suplemen, seng juga dapat diperoleh dari bahan makanan seperti kacang-kacangan, ikan laut, tiram, telur, daging dan lainnya. Seng juga diteliti sebagai salah satu pencegahan dismenorea karena dapat mengurangi sintesis prostaglandin melalui kemampuan sebagai anti inflamasi dan antioksidan dapat meningkatkan sirkulasi pembuluh darah mikro, sehingga kontraksi uterus akan berkurang menyebabkan syaraf-syaraf yang ada di uterus tidak terjepit dan nyeri menstruasi akan berkurang (Manuaba, Chandranita, dan Fajar, 2007 dalam Mundarti, Pratikto, \& Tribowo, 2014).

Hasil analisis data menunjukkan tidak ada hubungan yang signifikan antara tingkat konsumsi vitamin $\mathrm{E}$ dengan dismenorea primer diperoleh hasil $p$-value sebesar 0,144 $(\alpha>0,05)$. Penelitian ini tidak sejalan dengan hasil penelitian yang dilakukan oleh Herdanela dan Amirus, (2015) pada siswi di SMA Negeri 1 Pulau Panggung Tanggamus dengan pemberian vitamin E selama 5 hari (2 hari saat menjelang dan 3 hari saat menstruasi) efektif dalam menurunkan dismenorea. Penelitian lain yang dilakukan oleh Wahyuni (2018) dengan pemberian coklat hitam sebanyak 100gram yang memiliki kandungan magnesium, kalium, natrium, dan vitamin A, B1, (tiamin), B2 (riboflavin), D, dan E, mampu memblokir produksi prostaglandin sehingga dapat menurunkan nyeri saat menstruasi. Wanita dengan dismenorea memiliki konsentrasi kadar prostaglandin yang relatif tinggi dalam siklus menstruasinya. Oleh karena itu penekanan sintesis prostaglandin menjadi salah satu alternatif pengobatan, dengan adanya mekanisme efek dari vitamin E dapat menekan aktivitas enzim fosfolipase A2 sehingga menekan metabolisme dari asam arakidonat, hal tersebut akan menghambat produksi prostaglandin (Hutagaol, Arifuddin, dan Syamsudin, 2018). Tokoferol pada vitamin E ini juga berfungsi sebagai antioksidan memiliki kemampuan inhibisi dalam proses inflamasi, kerusakan sel membran dan regulasi trombosit maka vitamin $\mathrm{E}$ mempunyai peranan dalam mengurangi rasa nyeri saat haid. (Rishel dan Basyir, 2018). Selain kurangnya mengonsumsi sumber vitamin $\mathrm{E}$, dismenorea primer juga dapat disebabkan oleh beberapa faktor seperti usia menarch dini yang menyebabkan organ reproduksi belum dapat berfungsi secara optimal (Widjanarko, 2006), status gizi juga dapat menyebabkan dismenorea, seseorang yang mengalami overweight dapat beresiko dismenorea karena terdapat jaringan 
lemak yang berlebihan di pembuluh darah, sehingga darah yang mengalir saat menstruasi terganggu dan menimbulkan rasa nyeri (Sophia, Muda, dan Jemadi, 2013). Faktor stres juga bisa menyebabkan dismenorea karena dapat memproduksi hormon-hormon seperti kortisol dan adrenalin yang dapat menyebabkan peningkatan kontraksi otot rahim sehingga mengakibatkan rasa nyeri saat menstruasi (Sari \& Nurdin, 2015).

\section{DAFTAR PUSTAKA}

Almatsier, S. (2009). Prinsip Dasar Ilmu Gizi. Jakarta: Gramedia Pustaka Umum.

Casteli, N. W. A. (2018). Hubungan Tingkat Konsumsi Fe, Vitamin $\mathrm{C}$ dan Status Anemia Dengan Kejadian Dismenorea Pada Remaja Putri di SMA Negeri 1 Sukawati Kabupaten Gianyar Provinsi Bali. [Skripsi]. Denpasar: Jurusan Gizi, Politeknik Kesehatan Denpasar. https://www.scribd.com/document/400168 501/SKRIPSI-NI-WAYAN-ANISACASTELI-docx

Damayanti, N., Sunarsih, \& Utami, V. Wi. (2020). TERAPI ZINC DALAM MENURUNKAN NYERI MENSTRUASI ( DYSMENORRHEA ). Jurnal Kebidanan Malahayati, 6(3), 394-400. http://ejurnalmalahayati.ac.id/index.php/ke bidanan/article/download/1687/pdf

Devi, N. (2012). Gizi Saat Sindrom Menstruasi. Jakarta: PT Bhuana Ilmu Populer.

Direktorat Jendral, K. M. (2018). Tabel Komposisi Pangan Indonesia. Jakarta: Kementerian Kesehatan RI.

Farrah, A. M., Halim, B., \& Kaban, Y. B. (2017). Effectiveness of zinc supplementation in treating dysmenorrhea. Bali Medical Journal, 6(1), 34-37. https://doi.org/10.15562/bmj.v6i1.380

Febriani, D., Ariani, D., \& Kusumastuty, I. (2018). Pengaruh Konsumsi Susu Sapi Terhadap Penurunan Intensitas Nyeri Dismenore Primer Pada Siswi Jurusan Keperawatan Di SMKN 2 Malang. Journal of Issues in Midwifery, 2, 20-33. https://joim.ub.ac.id/index.php/joim/article /view/63/37

Hendarini, A. T. (2018). Pengaruh Body Image dan Kebiasaan Makan dengan Status Gizi Di SMAN 1 Kampar Tahun 2017. Jurnal Gizi (Nutrition Journal), 2, 138-145.

\section{SIMPULAN}

Terdapat hubungan antara tingkat konsumsi kalsium, seng dan vitamin E dengan kejadian dismenorea primer. Semakin baik tingkat konsumsi kalsium, seng dan vitamin E maka semakin rendah kejadian dismenorea. Oleh karena itu perlu diberikannya penyuluhan terkait alternatif pencegahan atau penanggulangan dismenorea khususnya mengenai peran zat gizi yang dapat digunakan sebagai terapi dismenorea.

https://journal.universitaspahlawan.ac.id/inde x.php/jurnalgizi/article/download/200/176

Herdanela, H., \& Amirus, K. (2015). Efektivitas Pemberian Vitamin E Dan Olahraga Terhadap Penurunan Dismenore Pada Siswi Di Sekolah Menengah Atas (SMA) Negeri I Pulau Panggung Tanggamus Tahun 2014. Jurnal Dunia Kesehatan, 4, 14-23. http://www.ejurnalmalahayati.ac.id/index. php/duniakesmas/article/view/419/354

Hutagaol, I. O., Arifuddin, S., \& Syamsudin, S. (2018). Pengaruh Suplementasi Vitamin E Terhadap Kadar Prostaglandin (PGF2 $\alpha$ ) dan Intensitas Nyeri Haid (Dysmenorrhea) Primer Pada Remaja Putri. The Southeast Asian Journal of Midwifery, 4(2), 70-75. http://www.journal-aipkind.or.id/3b4e32e31cb6-4951-8db2-f78be497aa03

Karlina, L. (2014). Penurunan Nyeri Dismenorea Primer melalui Kompres Hangat pada Remaja Effect of Warm Compress on Decreasing Primary Dysmenorrhea Pain in Adolescents. Jurnal Keperawatan Padjajaran, 3. http://jkp.fkep.unpad.ac.id/index.php/jkp/a rticle/view/104

Mardalena, I. (2017). Dasar-Dasar Ilmu Gizi Dalam Keperawatan. Yogyakarta: Pustaka Baru Press.

Mundarti, Pratikto, J., \& Tribowo, M. (2014). Pemberian Tablet Zink terhadap Tingkat Nyeri Dismninore Primer. Jurnal LINK, 10, 856-862. http://ejournal.poltekkessmg.ac.id/ojs/index.php/link/article/view/84

Nugroho, T., \& Indra, U. B. (2014). Masalah Kesehatan Reproduksi Wanita. Yogyakarta: Nuha Medika.

Putri, S. A., Yunus, M., \& Fanani, E. (2017). Hubungan Antara Nyeri Haid (Dismenore) Terhadap Aktivitas Belajar pada Siswi Kelas XI SMA Negeri 52 
Jakarta. Preventia: The Indonesian Journal of Public Health, 2(2), 85-92. http://journal.um.ac.id/index.php/preventia /article/view/10013

Rahman, N., Dewi, N. U., \& Armawati, F. (2016), Faktor-Faktor Yang Berhubungan Dengan Perilaku Makan Pada Remaja SMA Negeri 1 Palu. Jurnal Preventif, 7, 43-52. jurnal.untad.ac.id/jurnal/index.php/Prevent if/article/view/5818/4576

Ratnawati, A. (2017). Asuhan Keperawatan Pada Pasien Dengan Gangguan Sistem Reproduksi. P. B. Press, ed.

Rishel, R. A., \& Basyir, V. (2018). Pengaruh Pemberian Vitamin E Terhadap Kadar Prostaglandin (PGF2A) dan TNF Pada Penderita Dismenorea. Jurnal Ilmu Keperwatan Dan Kebidanan, 9(2), 57-64. https://docplayer.info/130488520-

Pengaruh-pemberian-vitamin-e-terhadapkadar-prostaglandin-pgf2a-dan-tnf-a-padapenderita-dismenorea.html

Sari, D., \& Nurdin, A. E. (2015). Artikel Penelitian Hubungan Stres dengan Kejadian Dismenore Primer pada Mahasiswi Pendidikan Dokter Fakultas Kedokteran Universitas Andalas. Jurnal Kesehatan Andalas, 4(2), 567-570. http://jurnal.fk.unand.ac.id/index.php/jka/a rticle/view/301

Setiawan, S. A., \& Lestari, L. (2018). Hubungan Nyeri Haid (Dismenore) dengan Aktivitas Belajar Sehari-Hari Pada Remaja Putri Kelas VII Di SMPN 3 Pulung. Jurnal Delima Harapan, 5(1), 24-31. https://doi.org/10.31935/delima.v5i1.5

Silviana, P. D. (2012). Hubungan antara karakteristik individu, aktivitas fisik, dan konsumsi produk susu dengan dysmenorrhea promer pada mahasiswi FIK dan FKM UI Depok. [Skripsi]. Depok: Program Sarjana Fakultas Kesehatan Masyarakat Program Studi Gizi Universitas Indonesia. http://lib.ui.ac.id/file?file=digital/2032059 7-S-Putri Dwi Silvana.pdf

Sophia, F., Muda, S., \& Jemadi. (2013). Faktorfaktor Yang Berhubungan Dengan Dismenore Pada Siswi SMK Negeri 10 Medan Tahun 2013. Jurnal Gizi, Kesehatan Reproduksi Dan Epidemiologi, 2. https://jurnal.usu.ac.id/index.php/gkre/article /view/4060/1894

Sukarni K, I. K., \& Wahyu, P. (2013). Buku Ajar Keperawatan Maternitas. Yogyakarta: Nuha Medika.

Tih, F. T. F., Azaria, C., Gunadi, J. W., Rumanti, R. T., Susanto, A. T., Santoso, A. A., \& Evitasari, F. T. (2017). Efek Konsumsi Suplemen Kalsium dan Magnesium terhadap Dismenore Primer dan Sindrom Premenstruasi pada Perempuan Usia 1923 Tahun. Global Medical \& Health Communication, 5(3), 159-166. https://ejournal.unisba.ac.id/index.php/gm hc/article/view/2161

Wahyuni, L. T. (2018). Pengaruh Konsumsi Coklat Hitam Terhadap Penurunan Tingkat Nyeri Haid (Dismenor Primer) Pada Mahasiswi Ilmu Keperawatan STIKES Ranah Minang Padang. Menara Ilmu, 12(2), 73-78. https://jurnal.umsb.ac.id/index.php/menara ilmu/article/viewFile/513/452

Widjanarko, B. (2006). Dismenore tinjauan terapi pada dismenore primer. Majalah Kedokteran Damianus, 5(1), 1-10. 